\title{
Psychological Impact of Repair Surgery in Cleft Lip and Palate
}

\author{
Amy J. Fletcher ${ }^{\mathrm{a}, \mathrm{d}}$, Jenny Hunt ${ }^{\mathrm{b}}$, Sue Channon ${ }^{\mathrm{b}}$, Vanessa Hammond ${ }^{\mathrm{c}}$
}

\begin{abstract}
Many of the psychological dimensions of cleft lip and palate for the individual, both in childhood and adulthood, have been researched extensively. However, little specific research has been conducted on the psychological impact of one of the most significant aspects of the condition, that of repair surgery. This article presents the current research in this area, focusing on the potential impact repair surgery has on attachment, coping and resilience, along with the implications for future research.
\end{abstract}

Keywords: Cleft lip and palate; Impact; Surgery

\section{Introduction}

Clefts of the lip and/or palate (CLP) are the most common congenital craniofacial anomaly, affecting around 1.7 per 1,000 live births worldwide [1] with around 1 in 700 affected babies born in the UK [2].

Clefts of the lip and palate have been researched for many years, but more recently the psychological impact of the condition has been investigated. In preparation for a research study on the experiences of mothers during the time of surgical repair of their babies' CLP, a thorough literature search was conducted using Swetwise, Scopus, Web of Science and OvidSP (which included Medline, EMBASE and PsychInfo). The following search terms were used: "Cleft lip

\footnotetext{
Manuscript accepted for publication August 15, 2012

${ }^{\mathrm{a}}$ Health Psychology Department, Beacon House, Gloucestershire Royal Hospital, Gloucester, GL1 3NN, UK

${ }^{\mathrm{b}}$ South Wales Doctoral Programme in Clinical Psychology, 11th Floor Tower Building, Park Place, Cardiff, CF10 3AT, UK

${ }^{\mathrm{c} C l e f t}$ Lip and Palate Service, Morriston Hospital, Heol Maes Eglwys, Morriston, Swansea, SA6 6NL, UK

${ }^{\mathrm{d} C}$ Corresponding author: Amy J. Fletcher, Health Psychology Department, Beacon House, Gloucestershire Royal Hospital, Gloucester, GL1 3NN,

UK. Email: amyj_fletcher@yahoo.co.uk
}

doi: http://dx.doi.org/10.4021/ijcp39w and palate", "lip repair", "palate repair" with combinations of "mothers", "parents", "surgery", "attachment", "Psychological", "adjustment", "visual difference", "visible difference", facial disfigurement" and "coping".

Generally the psychosocial research has focussed on the impact of living with CLP for the individual with general well-being and quality of life being particular areas of study [3-7]. Research into the impact of diagnosis on parents has highlighted surgery as a specific concern but interestingly whilst surgery is one of the most significant stages within the cleft lip and palate journey, there has been little research in this area.

Surgery is a major factor influencing quality of life in the early stages of the CLP journey [8]. In a large early study where 175 sets of parents were interviewed, both mothers and fathers placed repair of the cleft as an important concern on discovering the diagnosis [9]. Surgery was seen as the solution to the cleft, as parents showed prospective feelings of 'everything being well' following surgery. However as well as being a solution, surgery is also a source of significant concern for parents [10], a concern which becomes more important as surgery gets closer. Worries related to the procedure have included timing (of the procedure, duration and recovery), side effects, the care involved, whether additional tissue was required for the repair, techniques used, outcomes of surgery and pain. In a retrospective study focusing on parental experience, parents' anxieties around surgery included the anaesthetic, risks of infection, the possibility that surgery would not be successful and what their child would look like following the repair [11]. Other aspects of care by the team have also been identified as important to parents including communication with professionals, empathy, postsurgical care and discharge management; with the preparation for surgery, as well as the discharge, being more significant than the time of the surgery itself [8].

\section{Appearance in CLP}

A difference in appearance is perhaps the most obvious consequence of having a CLP with many families believing that surgery will make their child's life better through the chang- 
es in appearance [12]. This difference depends upon the type of cleft and its severity as well as other possible effects of the cleft, such as dental difficulties. Appearance is difficult to predict following surgery due to the child's growth contributing to the result in the future [13]. As a baby however, following the initial repair surgery, change in appearance may be dramatic, particularly if the cleft was prominent. An important consideration therefore is the expectation of the change in appearance following surgery. A discrepancy between the expected appearance of the baby and the reality can lead to feelings of grief and loss [14-15]. Adjustment is required from the anticipated 'perfect' baby and their baby with a visible difference [16].

\section{Coping and Adjustment}

Elements of coping and adjustment have been investigated in order to best understand how a family adapts to having a child with CLP. Expectations of having a healthy baby need to be assimilated as well as an understanding of the various elements of CLP, such as surgery. Social support has been highlighted as being useful in the process of coping, as well as perceived support from professionals involved in the child's care [11, 17]. Support from friends and family has been linked with lower distress, better adjustment and less negative family impact. This is thought to be due to social support providing greater feelings of belonging, self-esteem, a positive outlook and a greater sense of value. In terms of coping strategies, use of approach coping (seeking support, problem solving, logical analysis and positive appraisal) was associated with more positive adjustment compared to avoidant coping [17]. Social support was also identified as a coping strategy used by parents [18], as well as intensification of partnership, self-respect and fulfilment, with a positive approach being particularly important. The significance of support from other parents has also been highlighted [11, $15]$.

Riski [15] identified two important considerations in terms of parental coping. Firstly, needs of parents tend to be greater at times of transition (such as surgery) and therefore, support and coping should be emphasised at these times. Secondly, parents can be highly diverse in their experience and needs, as well as their abilities to cope and therefore, a standardised approach to supporting families may not be sufficient or appropriate.

The impact of parental expectations on the perception of the baby has been considered as a possible framework to understand parental adaptation. Beaumont [14] used personal construct theory (which is based on the making and testing of hypotheses in order to understand the world) to understand the reactions to diagnosis. The results were suggestive of a process similar to the stages observed in bereavement, as a way of adjusting to the unexpected nature of CLP.

\section{Resilience}

Resilience, defined as 'the ability to withstand and rebound from crisis and adversity' [19] is a growing area of research. This concept has been studied from the perspective of the individual as well as from the family unit. Family resilience is not thought of as merely the use of family members as a resource: Instead, adverse events have an impact on the whole family and therefore can affect the family's functioning, which in turn can affect elements which aid resilience. Resilience factors within a family can include having a positive outlook, spirituality, flexibility, problem solving, cohesion, communication and shared recreation [19-20]. Differences in resilience may be apparent for a short term crisis compared to one which has multiple stressors and is more persistent. Long term medical conditions present unique challenges to a family. The Family-Systems-Illness Model [21-22] provides a framework for those who are facing a chronic illness. It focuses on the psychosocial type of illness (awareness of its onset, course, outcome, incapacitation and level of uncertainty), the time phases of the illness and family system variables (such as family scripts about illness and coping, normalisation of challenges, meaning made from the illness, beliefs about the cause of illness and so on). It is thought that this model offers a collaborative practice between professionals and families to aid coping and adaptation. This model has been applied to a number of illnesses, including families facing genetic conditions and cancer [2324] and may have relevance within CLP, at significant times within the treatment journey, such as the surgery. Resilience has begun to be studied within CLP, but initial studies have been focussed on the resilience of the individuals born with CLP themselves $[5,25]$ rather than their families.

\section{Attachment}

Change in appearance may not only have an impact on a family's coping and resilience but may also affect the bonding relationship between parent and child. Early attachment is a reciprocal process, relying on the reactions between a primary care giver and the baby. It occurs through a mother's attunement to her baby, including aspects such as: movement, touch, facial expression and vocalisations. The interaction process in attachment is activated by various conditions such as: stress, fear, unfamiliarity and hunger [26-27]. This interaction aids the baby's ability to recognise and self-regulate their emotions as well as other bodily sensations such as hunger and thirst. If the baby's ability to form facial expressions (such as smiling) is affected, as it might be with a cleft lip and palate, then the relationship may be affected [28-29].

It is thought that childhood attachment tends to become apparent at around six months of age [28] and therefore experiences around this time could be significant. In terms of 
the CLP journey then, issues such as surgical repair could be disruptive.

A study by Clements and Barnett [30] looked at attachment in a variety of birth defects including CLP. Although it was found that CLP could interfere with emotional and verbal responsiveness, parental care-giving behaviours were more likely to predict attachment styles than the medical condition concerned. Parenting quality also seemed to be better for those children with more severe facial disfigurements. Most evidence seems to suggest that there are no significant differences in attachment between those with CLP and control groups [27, 31-34] although there are some contrasting findings in which 12 month olds born with cleft palate (CP) had lower attachment security; however the differences then disappear by two years of age [33]. Timing of repair may be significant with one study indicating that those with a standard repair (between three and four months of age) show worse mental development scores at 18 months than those with a neonatal repair [35]. This was thought to be linked to mother-infant interactions at two months of age and emphasises the importance of early interaction and potentially how the repair of CLP may have an impact. Further research by Hentges et al [36] found that this impact on mental development persists when the children are 7 years old. They concluded that the difference in mother-child interactions was the mediating factor between the cleft being repaired at $3-4$ months and lowered IQ scores.

\section{Implications for Further Research}

This literature shows that repair surgery in CLP should not be seen as merely a treatment in the CLP journey but as a process that is a significant concern for parents; the results of surgery and the potentially significant changes in appearance can in turn affect parental coping, resilience and attachment. However, at present, this impact is, at best, speculation as research has not focused on the psychosocial aspects of repair surgery on the family unit surrounding the individual with CLP. Such research could add to the resilience and adjustment literature as well as providing more practical applications to the perioperative care of CLP repair surgery and care relating to the parents within the hospital setting.

\section{Conflict of Interest}

The authors declare no conflict of interest relating to this article.

\section{References}

1. Mossey PA, Little J, Munger RG, Dixon MJ, Shaw WC.
Cleft lip and palate. Lancet. 2009;374(9703):1773-1785.

2. 'Understanding Cleft Lip and Palate' (2009). Retrieved 28 April 2011 from http://www.clapa.com/medical/ cleft_lip_article/107/

3. Hunt O, Burden D, Hepper P, Johnston C. The psychosocial effects of cleft lip and palate: a systematic review. Eur J Orthod. 2005;27(3):274-285.

4. Hunt O, Burden D, Hepper P, Stevenson M, Johnston C. Self-reports of psychosocial functioning among children and young adults with cleft lip and palate. Cleft Palate Craniofac J. 2006;43(5):598-605.

5. Feragen KB, Borge AI, Rumsey N. Social experience in 10-year-old children born with a cleft: exploring psychosocial resilience. Cleft Palate Craniofac J. 2009;46(1):65-74.

6. Marcusson A, Akerlind I, Paulin G. Quality of life in adults with repaired complete cleft lip and palate. Cleft Palate Craniofac J. 2001;38(4):379-385.

7. Berger ZE, Dalton LJ. Coping With a Cleft II: Factors Associated With Psychosocial Adjustment of Adolescents With a Cleft Lip and Palate and Their Parents. Cleft Palate Craniofac J. 2011;48(1):82-90.

8. Stone MB, Botto LD, Feldkamp ML, Smith KR, Roling L, Yamashiro D, Alder SC. Improving quality of life of children with oral clefts: perspectives of parents. J Craniofac Surg. 2010;21(5):1358-1364.

9. Spriestersbach DC. Counselling parents of children with cleft lips and palates. Journal of Chronic Diseases. 1961; 13(3): 244-252.

10. Chuacharoen R, Ritthagol W, Hunsrisakhun J, Nilmanat K. Felt needs of parents who have a 0 - to 3-month-old child with a cleft lip and palate. Cleft Palate Craniofac J. 2009;46(3):252-257.

11. Johansson B, Ringsberg KC. Parents' experiences of having a child with cleft lip and palate. J Adv Nurs. 2004;47(2):165-173.

12. Weatherley-White RC, Eiserman W, Beddoe M, Vanderberg R. Perceptions, expectations, and reactions to cleft lip and palate surgery in native populations: a pilot study in rural India. Cleft Palate Craniofac J. 2005;42(5):560564.

13. Berkowitz, S. The Cleft Palate Story. USA: Slack Incorporated, 2006.

14. Beaumont D. Exploring parental reactions to the diagnosis of cleft lip and palate. Paediatr Nurs. 2006;18(3):1418.

15. Riski JE. Parents of children with cleft lip and plate. Clin Commun Disord. 1991;1(3):42-47.

16. Bradbury ET, Hewison J. Early parental adjustment to visible congenital disfigurement. Child Care Health Dev. 1994;20(4):251-266.

17. Baker SR, Owens J, Stern M, Willmot D. Coping strategies and social support in the family impact of cleft lip and palate and parents' adjustment and psychological 
distress. Cleft Palate Craniofac J. 2009;46(3):229-236.

18. Schuster M, Kummer P, Eysholdt U, Rosanowski F. [Social orientation of parents of children with cleft lip and palate]. HNO. 2003;51(6):507-512.

19. Walsh D, Downe S. Appraising the quality of qualitative research. Midwifery. 2006;22(2):108-119.

20. Black K, Lobo M. A conceptual review of family resilience factors. J Fam Nurs. 2008;14(1):33-55.

21. Rolland JS. Families, illness and disability: an integrative treatment model. New York: Basic Books, 2004.

22. Rolland JS, Walsh F. Facilitating family resilience with childhood illness and disability. Curr Opin Pediatr. 2006;18(5):527-538.

23. Street E, Soldan J, Grey J. A family affair: Themes and perspectives of counselling in genetic services. Counselling Psychology Review. 2000; 15(1): 4-11.

24. Rolland JS. Cancer and the family: an integrative model. Cancer. 2005;104(11 Suppl):2584-2595.

25. Feragen KB, Kvalem IL, Rumsey N, Borge AI. Adolescents with and without a facial difference: The role of friendships and social acceptance in perceptions of appearance and emotional resilience. Body Image. 2010;7(4):271-279.

26. Bowlby J. The making and breaking of affectional bonds. I. Aetiology and psychopathology in the light of attachment theory. An expanded version of the Fiftieth Maudsley Lecture, delivered before the Royal College of Psychiatrists, 19 November 1976. Br J Psychiatry. 1977;130:01-210.

27. Hoeksma JB, Koomen HMY, Van den Boom D. The development of early attachment behaviours. Early Development and Parenting. 2006; 5(3): 135-147.
28. Ainsworth MDS, Bowlby J. An ethological approach to personality development. American Psychologist, 1991; 46(4): 333-341.

29. Rees C. Childhood attachment. Br J Gen Pract. 2007;57(544):920-922.

30. Clements M, Barnett D. Parenting and attachment among toddlers with congenital anomalies: Examining the strange situation and attachment Q-Sort. Infant Mental Health Journal. 2002; 23(6): 625-642.

31. Coy K, Speltz ML, Jones K. Facial appearance and attachment in infants with orofacial clefts: a replication. Cleft Palate Craniofac J. 2002;39(1):66-72.

32. Speltz ML, Endriga MC, Fisher PA, Mason CA. Early predictors of attachment in infants with cleft lip and/or palate. Child Dev. 1997;68(1):12-25.

33. Maris CL, Endriga MC, Speltz ML, Jones K, DeKlyen $M$. Are infants with orofacial clefts at risk for insecure mother-child attachments? Cleft Palate Craniofac J. 2000;37(3):257-265.

34. Endriga MC, Speltz ML. Face-to-face interaction between infants with orofacial clefts and their mothers. J Pediatr Psychol. 1997;22(4):439-453.

35. Murray L, Hentges F, Hill J, Karpf J, Mistry B, Kreutz $\mathrm{M}$, Woodall $\mathrm{P}$, et al. The effect of cleft lip and palate, and the timing of lip repair on mother-infant interactions and infant development. J Child Psychol Psychiatry. 2008;49(2):115-123.

36. Hentges F, Hill J, Bishop DV, Goodacre T, Moss T, Murray L. The effect of cleft lip on cognitive development in school-aged children: a paradigm for examining sensitive period effects. J Child Psychol Psychiatry. 2011;52(6):704-712. 